\title{
Um olhar sobre a legislação dos estágios: na prática a teoria é outra?
}

\author{
A look at the legislation of stages: in practice the theory is another?
}

\author{
¿Un vistazo a la legislación de la pasantía: en la práctica la teoría es otra?
}

Recebido: 10/03/2014

Érico Lopes Pinheiro de Paula ${ }^{1}$

Aprovado: 18/07/2014

Esse artigo apresenta estudo sobre a legislação vigente no Brasil a respeito dos estágios supervisionados da educação profissional. São dois os objetivos dessa iniciativa: a) reunir referências para auxiliar no debate institucional sobre as políticas de estágio e b) destacar, para as comissões internas nos cursos, as principais orientações legais. 0 trabalho consistiu em revisão bibliográfica, da legislação e do material reunido no repositório "Pareceres e resoluções sobre estágio" do Ministério da Educação (MEC). Os resultados permitiram reconhecer heterogeneidade e ambiguidade no marco legal, o que foi constatado pelo volume e teor das consultas apresentadas ao Conselho Nacional de Educação (CNE) desde 1996. As políticas institucionais a respeito dos estágios em instituições de ensino superior (IES) merecem profundo debate político que não se encontra realizado até o momento.

Descritores: Currículo; Prática Profissional; Legislação como Assunto.

This article presents a study on current legislation in Brazil about supervised internships of education professionals. There are two objectives for this initiative: a) gather references to assist in the institutional debate on the internships policy and b) highlight, to courses internal committees, the main legal guidelines. The work consisted of a literature review, the legislation review and the review of the material gathered in the repository "Opinions and resolutions on internship" of the Ministry of Education (MEC). The results allowed to recognize heterogeneity and ambiguity in the legal framework, which was evidenced by the volume and content of the queries submitted to the National Education Council (CNE) since 1996. Institutional policies regarding internships in higher education institutions (HEIs) deserve deep political debate that is not done yet.

Descriptors: Curriculum; Professional Practice; Legislation as Topic.

En este artículo se presenta un estudio sobre la legislación vigente en Brasil acerca de la práctica supervisada de la educación profesional. Hay dos objetivos para esta iniciativa: a) recopilar referencias para ayudar en el debate institucional acerca de las políticas de práctica supervisada y b) destacar, para los comités internos de cursos, las principales directrices legales. El trabajo consistió en una revisión de la literatura de la legislación y del material recogido en los "dictámenes y resoluciones sobre el escenario" del repositorio del Ministerio de la Educación del Brasil (MEC). Los resultados permitieron reconocer la heterogeneidad y la ambigüedad en el marco legal, que se evidencia por el volumen y el contenido de las consultas enviadas al Consejo Nacional de Educación del Brasil (CNE) desde 1996. Las políticas institucionales de práctica supervisada en el instituciones de enseñanza superior (IES) merecen un debate político profundo que no se realiza aún.

Descriptores: Curriculum, Práctica Profesional, Legislación como Asunto.

\footnotetext{
${ }^{1}$ Cientista Social. Pedagogo. Especialista em Divulgação de Ciências. Mestrando no Programa de Pós-Graduação em Educação da UFTM. Supervisor do Núcleo de Estágios da UFTM. erico@proens.uftm.edu.br
} 


\section{INTRODUÇÃO}

responsabilidade de oferecer suporte

A às atividades de estágios na Universidade Federal do Triângulo Mineiro (UFTM) é do Núcleo de Estágios (NuEG) - responsável por funções consultiva, administrativa e executiva -, que atua junto no âmbito da PróReitoria de Ensino (PROENS) desde 2011.

Enquanto Faculdade de Medicina do Triângulo Mineiro (FMTM), desde 1971 até a adesão ao Programa de Apoio a Planos de Reestruturação e Expansão das Universidades Federais (REUNI), as deliberações sobre estágios nessa instituição eram conduzidas exclusivamente pela Coordenação Geral da Graduação em Medicina. A partir de 2007, com o ingresso no REUNI, a UFTM passou a ter 24 cursos de graduação e oito cursos técnicos profissionalizantes. Hoje esse panorama revela para a universidade um desafio - o de lidar com a heterogeneidade de pressupostos e procedimentos acerca dos estágios - seja no âmbito das Comissões Internas de Estágios (CIEs), em cada curso, seja no Conselho de Ensino (COENS).

Como ato educativo, os estágios supervisionados na formação profissional são regulamentados no Brasil pela lei federal 11.788 de 25 de setembro de 2008 (Lei do estágio) ${ }^{1}$. Embora não seja um marco legal propriamente recente, quando observadas as formas pelas quais esses componentes curriculares são autorizados pelos sistemas e oferecidos pelas instituições de ensino no país - tanto na educação básica quanto no ensino superior, incluída a pós-graduação se reconhece grande heterogeneidade e ambiguidade.

A título de ilustração, a partir de registros coligidos na PROENS, se observa a grande quantidade de memorandos enviados para solicitar celebração de convênios com concedentes - o que se tornou dispensável, e consideravelmente oneroso, após 2008. Entre docentes, coordenadores e supervisores, geralmente são encontradas concepções que não atentam para princípios importantes da lei 347 do estágio, expressas por: manutenção da nomenclatura "estágio extracurricular" nos regulamentos internos de curso, prática de substituição de atividades (ou abono de faltas) na carga horária obrigatória, não observação da obrigatoriedade dos termos de compromisso de estágio para a formalização, contagem de qualquer horário em atendimento de sala (supervisão) como atividade prática, emissão de declarações e certificados para fechamento da atividade, entre outros procedimentos sem respaldo legal hoje.

Outra dimensão igualmente relevante nas observações do NuEG diz respeito ao entendimento que têm os docentes, bem como os colegiados nos cursos, sobre a jornada de trabalho para as componentes curriculares que apresentam atividades práticas. Por exemplo, para composição da carga horária atribuída a um profissional docente, a legislação, as diretrizes curriculares nacionais específicas dos cursos e os projetos pedagógicos, privilegiam critérios e estabelecem pressupostos que não apresentam organicidade plena.

Entende-se que existem matizes epistemológicas a distinguirem áreas de formação e/ou conhecimento - como nas tecnológicas, saúde ou licenciaturas -, bem como é reconhecido nos conselhos profissionais a legitimidade para estabelecerem prerrogativas complementares. Contudo se defende que a legislação educacional, os estatutos das instituições e o princípio da gestão democrática, podem oferecer as condições para serem definidos projetos pedagógicos e normas internas que conduzam os estágios em direção à qualidade e à emancipação almejados pelos profissionais da educação e pela sociedade em geral - com base em sinergia e cooperação.

0 primeiro ponto a ser esclarecido diz respeito ao alcance restrito que a lei do estágio tem sobre diversas situações que envolvem essa atividade. Marcadamente, a lei $11.788 / 08^{1}$ define tão somente os aspectos jurídicos dessa relação - entre instituição concedente, instituição escolar e

REFACS(online)2014;2(3):346-356 
estudante, com vistas à manutenção de direitos e à coibição de abusos na utilização da força de trabalho. A mesma lei prevê que "normas complementares" devem ser estabelecidas pelas instituições de ensino. Por outro lado, na ausência de consensos (entre e) dentro das instituições de ensino, recai sobre o Conselho Nacional de Educação (CNE) a decisão final sobre as controvérsias. Assim, os objetivos deste artigo são: analisar os princípios pedagógicos, relativos a estágio, contemplados na legislação educacional: $\operatorname{LDB}^{2}$ e lei do estágio ${ }^{1}$; e sintetizar as principais decisões que sustentam os pareceres do CNE reunidos em repositório eletrônico do MEC.

\section{MÉTODO}

0 estudo aqui descrito caracteriza-se como pesquisa documental e exploratória realizada sob demanda da Pró-Reitoria de Ensino da UFTM, durante o primeiro semestre de 2014 para a revisão do marco legal. Os textos foram reunidos, em formato eletrônico, a partir dos repositórios oficiais disponíveis na internet.

Para selecionar o material foi definido como critério cronológico a promulgação da $\mathrm{LDB}^{2}$ - no que se refere aos documentos do Governo Federal - e para reunir os pareceres do CNE recorreu-se ao portal do MEC. Assim, o trabalho aqui exposto consistiu na análise dos principais preceitos - a partir de leitura aprofundada sobre a $\operatorname{LDB}^{2,3}$ e a lei do estágio $^{1}$ - e em uma síntese dos pareceres e resoluções do CNE relacionados.

Pensando os estágios como campo de conhecimento, no qual ganha contornos de atividade investigativa ${ }^{4}$, admite-se sua realidade polêmica, controversa e polissêmica. Também, como espaço de formação no qual estão imbricados elementos práticos e teóricos ${ }^{5}$, se é impelidos a conceber os estágios como possibilidade concreta de superar essa dicotomia que condiciona o desenvolvimento profissional desde a formação inicial. Diante do contexto contemporâneo.

Escolheu-se trabalhar com a legislação vigente para se ater aos critérios 348 mínimos a serem contemplados em regimentos, regulamentos e projetos pedagógicos. Conforme destacado, há a consciência de que não é o marco legal que determina todas as condições e possibilidades pedagógicas em que são realizados os estágios. Algumas definições acerca desse ato educativo decorrem em larga medida das instituições concedentes as quais divergem muito em seus procedimentos burocráticos, especialmente as públicas.

De maneira complementar, um estágio de sucesso também se caracteriza pela contribuição efetiva para com os processos, produtos e serviços desenvolvidos pelas concedentes - visando sempre o benefício de toda a sociedade e o aprimoramento da prática profissional.

Nesse sentido, a despeito das divergências conhecidas (na gestão de pessoas e dos recursos humanos, tanto nas empresas concedentes quanto nos órgãos públicos), e para além da interação com as demandas mais amplas da sociedade em geral, optou-se por fazer o levantamento dos documentos oficiais. Sendo a legislação apenas uma fração das orientações e diretrizes a serem consideradas, procurouse também regulamentação decorrente do CNE, para ilustrar melhor o debate e completar e o quadro das referências. No sítio institucional do Ministério da Educação (MEC), encontram-se todos os pareceres e resoluções reunidos em um mesmo repositório: "Pareceres e Resoluções sobre Estágio".

\section{RESULTADOS}

Nesse levantamento foram reunidos os seguintes documentos, conforme os critérios eleitos: duas leis federais, cinco resoluções e 16 pareceres. Com relação às resoluções, uma delas foi emitida pela Câmara da Educação Superior (CES), duas pela Câmara de Educação Básica (CEB) e duas pelo Conselho Pleno (CP) do CNE. Quanto aos pareceres, 12 foram emitidos pela CES e quatro pela CEB.

Com análise documental foram destacados dois conceitos fundamentais:

REFACS(online)2014;2(3):346-356 
vínculo empregatício e ato educativo. Levando em conta a proporção de pareceres frente à legislação e às resoluções, sobre estágios, se verificou contestações relativas a seguro obrigatório, carga horária obrigatória, prática como componente curricular, formação profissional na educação básica, entre outros aspectos.

Foi realizado também levantamento auxiliar, para conhecer literatura acadêmica a respeito de estágios supervisionados, na tentativa de encontrar subsídios teóricos para os questionamentos empreendidos. A busca no portal SciELO (Scientific Electronic Library Online), não retornou resultados significativos - tomando por base o período de 2008-2014.

\section{DISCUSSÂO}

\section{Análise da legislação}

0 primeiro aspecto a ser considerado nessa breve análise refere-se ao fato de que o marco legal da educação não proporciona definições pontuais e específicas do ponto de vista pedagógico, não parte de premissas ou princípios homogêneos, quando se trata de estágios.

Encontra-se nos 92 artigos contidos na Lei de Diretrizes e Bases da Educação ${ }^{2}$ apenas o artigo 82 que trata particularmente da matéria. Analisando a lei que sustenta a educação no Brasil, apenas nesse artigo aparece o conceito "estágio" (quatro ocorrências) que genericamente ajuda a definir o papel dos sistemas de ensino em sua responsabilidade sobre as "normas para realização dos estágios dos alunos regularmente matriculados no ensino médio ou superior em sua jurisdição"2. Ou seja, o consenso à época da promulgação da lei não ofereceu nenhum princípio educativo diretamente relacionado a estágio que permitisse registro definitivo.

Discriminar o estudante do trabalhador é fundamental em vários aspectos, por isso a lei é objetiva para determinar que inexista vínculo empregatício para o estagiário - mesmo quando ele recebe bolsa de estágio, tem seguro contra acidentes e cobertura previdenciária. Essa definição pode ser 349 muito útil para a gestão de pessoas, administração (pública e de empresas) e para o Ministério do Trabalho, porém supõese que é insuficiente do ponto de vista didático-pedagógico. É preciso ter em mente que a história do estágio inicia-se com as escolas de artes e ofícios e o ensino industrial desde a virada do século 20, portanto intimamente ligada à prática profissional.

Foi na década de setenta, com a implantação da Lei Federal no 5.692/71, que os estágios supervisionados ganharam força e cresceram em importância, uma vez que o Parecer CFE no 45/72, do extinto Conselho Federal de Educação, considerou o estágio profissional supervisionado como obrigatório para as habilitações profissionais técnicas dos setores primário e secundário da economia, bem como para algumas ocupações da área de saúde, permanecendo livre para as demais ocupações do setor terciário da economia, ou seja, das áreas de comércio e serviços $5: 7$.

A lei $11.788 / 08^{1}$ é o instrumento que definiria o estágio em alguns de seus contornos pedagógicos, em consonância com a nova Constituição Federal ${ }^{6}$, a nova $\operatorname{LDB}^{2}$ e em substituição à lei de estágios anterior (Lei 6.494/77), promulgada ainda sobre o regime militar. De fato, a redação abre com a definição direta de que estágio é um "ato educativo", importante noção para distinção entre exercício (ou prática) profissional e formação profissional, o que leva a consequências didáticas mais tangíveis.

Não obstante, o primeiro artigo em seu parágrafo único destaca aquela que reconhecidamente configura a maior preocupação dos legisladores: distinguir o estágio de um vínculo empregatício. No $\S 1$ o desse mesmo artigo revela-se o limite que a lei tem ao estabelecer fundamentos $\mathrm{e}$ consensos que abarquem a generalidade dos cursos de formação profissional: "o estágio faz parte do projeto pedagógico do curso". Analisando alguns pontos da lei do estágio ${ }^{1}$ atual são destacáveis alguns aspectos controversos:

Art. 10 Estágio é ato educativo escolar supervisionado, desenvolvido no ambiente de

REFACS(online)2014;2(3):346-356 
trabalho, que visa à preparação para o trabalho produtivo de educandos que estejam freqüentando o ensino regular em instituições de educação superior, de educação profissional, de ensino médio, da educação especial e dos anos finais do ensino fundamental, na modalidade profissional da educação de jovens e adultos.

$\S 10$ o estágio faz parte do projeto pedagógico do curso, além de integrar o itinerário formativo do educando.

$\S 2 o \quad 0$ estágio visa ao aprendizado de competências próprias da atividade profissional $e$ à contextualização curricular, objetivando o desenvolvimento do educando para a vida cidadã e para o trabalho (grifos nossos) ${ }^{1}$

Por princípio, fica clara a responsabilidade atribuída às instituições, concedente e de ensino, em relação a fins e meios para realização de determinado plano de atividades. À instituição campo de estágio cabe proporcionar os recursos físicos, a supervisão técnica e o clima organizacional propício para o aluno inserir-se no cotidiano das relações produtivas em determinada profissão. Ve-se na expressão "ambiente de trabalho" um grande interesse em caracterizar a concedente como universo de relações estritamente trabalhistas. Nesse tocante vigora a fiscalização do Ministério Público do Trabalho, o que não será objeto desse estudo. Em seguida se tratará de sintetizar as orientações do CNE, porém cumpre ainda destacar:

Não existe a obrigatoriedade legal da empresa ou de qualquer ente público de contratar estagiário. Se o faz, deve ter em mente que o estágio tem como objetivo proporcionar aprendizado prático ao estudante, o que caracteriza, na prática, o seu engajamento na preparação deste para o mercado de trabalho [...] não há como confundir o estagiário com o empregado. Este, contratado para o desenvolvimento de atividades necessárias à consecução, pela empresa, dos objetivos propostos, nos termos da legislação trabalhista, com obrigações $e$ direitos. Aquele, inserido na empresa em condições especiais, sem vínculo empregatício, cuja atividade representa uma complementação do ensino recebido, necessária ao estudante, para a inserção futura no mercado de trabalho estará sendo supervisionado pela instituição de ensino a que se vincula, responsável pelo programa de estágio $5: 15$.

À instituição de ensino cabe então na ausência de definições prévias decorrentes da $\mathrm{LDB}^{2}$, dos conselhos profissionais ou dos sistemas de ensino determinar as modalidades, condições e normas dos estágios em seu projeto pedagógico de curso. Pela experiência desenvolvida pelo NuEG, se observa projetos que apresentam ainda redação descontextualizada da nova lei ${ }^{1}$ :

Art. $3 o$ o estágio [...] não cria vínculo empregatício de qualquer natureza, observados os seguintes requisitos:

I - matrícula e freqüência regular do educando [...];

II - celebração de termo de compromisso entre o educando, a parte concedente do estágio e a instituição de ensino;

III - compatibilidade entre as atividades desenvolvidas no estágio e aquelas previstas no termo de compromisso.

§ 10 o estágio, como ato educativo escolar supervisionado, deverá ter acompanhamento efetivo pelo professor orientador da instituição de ensino e por supervisor da parte concedente, comprovado por vistos nos relatórios [...] e por menção de aprovação final.

\& 20 o descumprimento de qualquer dos incisos deste artigo ou de qualquer obrigação contida no termo de compromisso caracteriza vínculo de emprego do educando com a parte concedente do estágio para todos os fins da legislação trabalhista e previdenciária ${ }^{1}$ (grifos nossos).

É reconhecível também nesse terceiro artigo que o objetivo de caracterizar a ausência do vínculo empregatício, como já ocorre desde a $\mathrm{LDB}^{2}$, é prioritário dentro da lei do estágio ${ }^{1}$. No caso de matrícula e frequência em instituição de ensino, bem como na celebração de termo de compromisso, vê-se destaque para preceitos burocráticos e legais a serem respeitados durante a execução de toda atividade. Não

REFACS(online)2014;2(3):346-356 
obstante, ainda se encontra determinadas estruturas de cursos que permitem conclusão de estágio sem que o aluno seja convidado para celebrar algum termo de compromisso.

No caso da compatibilidade entre as atividades, desenvolvidas pelo estudante no campo, e o currículo do curso vale ressaltar que a autoridade pedagógica plena que se impõe sobre projetos pedagógicos, CIEs e, no limite, colegiados. 0 princípio constitucional da gestão democrática da educação impede de defender a tendência de centralização da normatização sobre estágios, no âmbito de uma pró-reitoria, por exemplo. Porém o que se pretende debater é até que ponto existe a possibilidade de uma política institucional universitária, ou se é necessário investir na iniciativa de promover autonomia plena dos cursos em relação à matéria.

\section{Pareceres e resoluções do CNE}

Sem esquecer a prioridade dada na legislação à distinção entre os estagiários e os recursos humanos das instituições campo, se privilegia aqui a perspectiva da identidade universitária a ser assumida por uma instituição de ensino.

A referida instituição (UFTM) se ampara no marco legal para reivindicar que os docentes, toda comunidade em cada curso, têm papel protagonista nas determinações de todas as condições em que os estágios são realizados, sem que para isso se eximam do compromisso de pensar a relação dessa universidade (em geral) com a sociedade e com o mundo do trabalho.

Se a lei de estágio ${ }^{1}$ complementa o esforço legislativo em tornar definitiva a distinção entre estagiário e empregado, desde 1997 é reunido outro empenho para definir os critérios didático-metodológicos que pautam essa atividade. Para uma dimensão do debate, em 4/8/2004 é emitido o Parecer CNE/CES n. $\stackrel{0}{ } 228^{7}$ que ilustra consulta feita para esclarecer sobre divergências entre a $\operatorname{LDB}^{2}$ e a antiga lei de estágios. Constata-se inclusive de que o CNE não analisa naquele momento aspectos exclusivamente pedagógicos, mas também jurídicos, dado o caráter ambíguo de determinadas prescrições legais:
Resta uma contradição entre as determinações das Leis 9.394/96 e 6.494/77 em relação ao seguro contra acidentes, que é opcional conforme a primeira, e obrigatório conforme a outra. Neste caso, deve-se seguir a determinação da Lei 9.394/96, e o seguro contra acidentes não deve ser obrigatório ${ }^{7: 3}$.

No que tange às licenciaturas, outra polêmica já é notada no ano seguinte à promulgação da $\mathrm{LDB}^{2}$, em um parecer que sugere parte integrante a esta lei, o CNE/CES no 744 de 3/12/978. Em seu artigo primeiro fica definido que as práticas de ensino são "as atividades desenvolvidas com alunos e professores na escola ou em outros ambientes educativos em, no mínimo, 300 horas, sob acompanhamento e supervisão da instituição formadora", o que as distinguem prontamente dos estágios - já que esses ocorrem fundamentalmente em ambiente de trabalho específico ao desenvolvimento de competências profissionais. Posteriormente essa instrução é ratificada pelo parecer CNE/CES no 503 de 03/08/989, embora não seja incomum encontrar divergências relacionadas à composição de matrizes curriculares e distribuições de carga horária para cumprir diretrizes curriculares nacionais em quaisquer dos cursos.

Quatro anos antes de terminada a "década da Educação" a Resolução no 1 CNE/CP, em 18 de fevereiro de 200210, institui as diretrizes curriculares nacionais para a formação de professores da educação básica em nível superior (curso de licenciatura, de graduação plena). Essa resolução ainda não determina a composição da carga horária nesses cursos, porém torna explícito pela primeira vez um princípio didático e metodológico fundamental: a dimensão prática do currículo.

No $\S 1^{0}$ do artigo 12 , a resolução registra que a prática de ensino do estudante "art. 12 [...] § $1^{\mathrm{o}}$ [...] na matriz curricular, não poderá ficar reduzida a um espaço isolado, que a restrinja ao estágio, desarticulado do restante do curso"10. Podemos confirmar também que não é incomum encontrarmos nos docentes, que não têm aulas de "estágio supervisionado" atribuídas, a certeza de que não guardam nenhuma responsabilidade REFACS(online)2014;2(3):346-356 
sobre pensar o papel dessa componente prática na formação inicial do seu estudante. Temos registro do grande número de consultas enviadas ao NuEG a respeito de condições específicas que não atendem mais a demandas locais ou contextuais. Frequentemente essas condições estão previamente definidas (ou ausentes) nos projetos pedagógicos - o que só permite alteração por decisão colegiada - sob pena de estarem autorizando atividades com risco de vínculo empregatício, por conta do descolamento em relação ao seu projeto pedagógico respectivo. Ora, em seu artigo 13 a resolução é ainda mais contundente, ao asseverar que a "art. 13 [...] dimensão prática transcenderá o estágio [...] numa perspectiva transdisciplinar" 10. Porém, até aqui verificamos o quanto é precária a regulamentação acerca da prática dentro do estágio, exceto pela definição de ato educativo ${ }^{1}$ em sua articulação entre prática e currículo.

Para ilustrar, com base no Parecer CNE/CES no $33^{11}$ emitido em 1o/2/2007, é lícito pensar que quando a legislação impõe à instituição de ensino o dever de determinar as condições de realização para os estágios, nas universidades são nos colegiados em que essa deliberação acontece. Nessa consulta sugerida pelos cursos de graduação em enfermagem, coloca-se em foco a divergência que pode ocorrer entre orientações de conselhos profissionais, especialmente nos cursos da saúde, e opções definidas nos projetos pedagógicos. Mais uma vez o CNE é taxativo em declarar que:

Cabe aqui registrar, mais uma vez, que as Associações, Conselhos e outros órgãos de representação de categorias profissionais não têm competência para determinar normas $e$ controles sobre a atuação das Instituições de Educação Superior, relativamente às condições de oferta de cursos superiores ${ }^{11: 2}$.

Outro exemplo como esse, encontramos em 1이일 emitido o parecer CNE/CES no $362^{12}$ sobre consulta realizada pelos cursos de direito. Ao ser questionado o CNE sobre os Núcleos de Processo Jurídicos, que se instituem nos 352 cursos de graduação por recomendação do conselho profissional, registra que não existe estrutura operacional para que as Secretarias do MEC assumam a atribuição de avaliá-los, sendo que "com a absorção desse novo encargo, a atividade-fim da Secretaria de Educação Superior ficaria seriamente comprometida"12:5.

Mais uma vez fica patente que cabe às instituições de ensino determinarem as condições de estágio, para o que têm autoridade maior inclusive que os conselhos profissionais, e eventualmente fiscalizarem por elas. No caso das IFES, não se compartilha essa tarefa nem mesmo com a mantenedora ou com o órgão regulador.

Em 2/2/2005 o Parecer CNE/CES no $15^{13}$, voltando ao foco nas licenciaturas, propõe uma definição que busca garantir o equacionamento do marco legal ao mesmo tempo em que reforça uma concepção não dicotômica de currículo e de relação entre ambiente de trabalho e instituição de ensino: A prática como componente curricular é o conjunto de atividades formativas que proporcionam experiências de aplicação de conhecimentos ou de desenvolvimento de procedimentos próprios ao exercício da docência [ou qualquer outro exercício profissional]. Por meio destas atividades, são colocados em uso, no âmbito do ensino, os conhecimentos, as competências $e$ as habilidades adquiridos nas diversas atividades formativas que compõem o currículo do curso. As atividades caracterizadas como prática como componente curricular podem ser desenvolvidas como núcleo ou como parte de disciplinas ou de outras atividades formativas. Isto inclui as disciplinas de caráter prático relacionadas à formação pedagógica, mas não aquelas relacionadas aos fundamentos técnico-científicos correspondentes a uma determinada área do conhecimento. Por sua vez, o estágio supervisionado é um conjunto de atividades de formação, realizadas sob a supervisão de docentes da instituição formadora, e acompanhado por profissionais, em que o estudante experimenta situações de efetivo exercício profissional. $O$ estágio supervisionado tem o

REFACS(online)2014;2(3):346-356 
objetivo de consolidar e articular as competências desenvolvidas ao longo do curso por meio das demais atividades formativas, de caráter teórico ou prático ${ }^{13: 3}$ (grifos nossos).

De maneira definitiva, e conforme apresentado, o parecer CNE/CES no $23^{14}$ emitido em 2/2/2006 orienta que é das instituições de Educação Superior a autoridade e responsabilidade para "avaliar se os estudos, estágios e experiências profissionais" em unidades escolares - o que nos a entender que também em qualquer outra formação profissional que não a licenciatura - "merecem reconhecimento como equivalentes às exigências de Prática de Ensino - Estágio Supervisionado"14:1.

A partir desse entendimento, no caso da UFTM, se volta a lidar com o desafio de promover uma política institucional sobre estágios diante da heterogeneidade de concepções que fundamentam esse ato educativo no âmbito dos colegiados dos cursos - incluída a formação técnica em nível médio.

Com relação à carga horária para formação do professor da escola básica, a LDB em seu artigo 65 determinava que "A formação docente, exceto para a educação superior, incluirá prática de ensino de, no mínimo, trezentas horas"2, sinalizando a importância desse componente para além dos cursos técnicos, tecnológicos e industriais. Contudo apenas com a Resolução no 2 CNE/CP, de $19 / 02 / 2002^{15}$ é que foi instituída a duração e a carga horária dos cursos de licenciatura.

No inciso II do primeiro artigo fica decretado que é de "400 (quatrocentas) horas o estágio curricular supervisionado", porém foi criada outra polêmica já que só pode ter início "a partir da segunda metade do curso" 15 .

Sem o objetivo de esgotar a questão, parece que os fundamentos aqui propostos provocam ambiguidade: por um lado propõem que a prática seja distribuída ao longo do curso, por outro restringem a oportunidade do estágio obrigatório (prática por excelência) para a segunda metade do curso. Dessa divergência decorrem problemas para o estudante, como por 353 exemplo, a ausência de horário para realização de estágios nos últimos semestres de alguns cursos, devido à exigência crescente de horas em formação prática (tendência nos conselhos profissionais). Lembramos ainda que a expressão "segunda metade do curso" não é um consenso, conforme processos de consulta analisados pela PROENS em 2013.

Ainda sobre essa matéria, o Parecer no 232 CNE/CES, de 6/8/200216, baseado no que consta no Parecer no 109/02 CNE/CES recomenda:

Acrescente-se que, em articulação com o estágio supervisionado e com as atividades de natureza acadêmica, importa à instituição prever 400 horas de prática como componente curricular a se realizar desde o início do curso, o que pressupõe relacionamento próximo com o sistema de educação escolar ${ }^{16: 2}$.

A despeito de todo debate desde 1996, ainda se verifica outros dissensos nas licenciaturas que exigem o Parecer no 35 CNE/CEB, de 05/11/20035, onde figura no histórico do relatório preliminar que "o estágio é, essencialmente, curricular e, portanto, de natureza formativa e vinculado ao projeto pedagógico da escola [como instituição concedente] $]^{5: 1-2 " . ~}$

Também foi verificado que o histórico trata o assunto desde o âmbito da antiga lei de estágios, caracterizando precisamente qualquer estágio supervisionado como "estágio curricular" e não como um simples apêndice da atividade escolar, como se o não obrigatório fosse uma "atividade extracurricular"5:3. Existe ainda o parecer CNE/CES n.o 197, de 7/7/200417, que não altera o entendimento sobre a questão.

Por conta do debate provocado pelas licenciaturas em relação ao lugar da prática no currículo, que fora expresso no Parecer $\mathrm{n}^{\mathrm{o}}$ 35/2003 CNE/CEB5 ${ }^{5}$ os cursos superiores de graduação em tecnologia solicitam posicionamento do CNE. Fica declarado em $10 / 11 / 2004$, o parecer CNE/CEB no $34^{18}$ com o objetivo de sustar "momentaneamente" os efeitos do Parecer CNE/CEB 35/20035 e da Resolução CNE/CEB 1/200419. Ressalta-se também REFACS(online)2014;2(3):346-356 
que, a serem consideradas as especificidades dos respectivos cursos, no caso da formação em saúde o "acompanhamento efetivo" preconizado pela lei $11.788 / 08^{1}$ é realizado in loco no campo de estágio, com número reduzido de estudantes por docente. Essa realidade aplicada à formação docente para a educação básica exigiria um número de docentes no ensino superior que não é exequível.

Em relação às orientações para os estágios na educação básica profissionalizante, incluídas a EJA e a educação especial, o CNE estabelece a Resolução no1 pela Câmara de Educação Básica, 21/01/200419, instituindo as Diretrizes Curriculares Nacionais. Alguns preceitos pedagógicos importantes que incorrem sobre todo e qualquer estágio ficam exemplificados melhor, como por exemplo: no $\S 1^{\mathrm{o}}$ do art. $1^{\mathrm{o}}$ tem destaque o conceito de ato educativo e no art. $5^{\mathrm{o}}$ as modalidades em que podem se realizar (profissional obrigatório, profissional não obrigatório, sociocultural ou de iniciação cientifica obrigatório ou não, e civil).

Homologada em 4/4/2005 a Resolução CNE/CEB n⿳o $2^{20}$ modifica a redação do $\S 3^{\circ}$ do artigo $5^{\circ}$ da Resolução CNE/CEB $\mathrm{n}^{\mathrm{o}} 1 / 2004^{19}$, que se torna definitiva até o momento, detalhando que as modalidades de estágio profissional supervisionado "somente serão admitidas quando vinculadas a um curso específico de Educação Profissional, na modalidade formação inicial e continuada de trabalhadores e na modalidade Educação Profissional Técnica de nível médio".

Tendo em vista a autoridade que a legislação atribui a institutos e empresas de formação técnica profissional, por solicitação do SENAC Rio foi emitido em 8/11/2012 o Parecer CNE/CEB no $20^{21}$ a respeito de uma modalidade de prática que ganha corpo também no âmbito da graduação: a vivência profissional.

Fica claro o objetivo de proporcionar aos discentes o contato com a prática, esquivando-se de dois limites impostos aos estágios: a) não podem ocorrer antes da metade do curso (Resolução no 2/2002
CNE/CP15) e b) quando não obrigatório impõe às concedentes a obrigatoriedade da contraprestação (art. 12 da lei do estágio ${ }^{1}$ ). Embora diferente da prática como componente curricular, que acontece no âmbito do ensino (na instituição escolar), também difere do estágio na medida em que: Caracteriza-se por atividades de prática profissional orientada e acompanhada de perto pelos profissionais orientadores, as quais são realizadas graças ao regime de parcerias com empresas do setor ou segmento produtivo diretamente relacionadas ao curso [porém, geralmente em parcerias com empresas]. O ambiente de aprendizagem é muito mais de laboratório que de situação real de trabalho, o que não caracteriza o estágio profissional supervisionado. As duas alternativas programáticas e curriculares encontram amparo na legislação e normas educacionais vigentes, desde que expressamente previstas no respectivo projeto político-pedagógico do curso em questão e intimamente vinculadas aos resultados de aprendizagem almejados ${ }^{21: 4}$.

Um último parecer reunido no repositório "Pareceres e Resoluções sobre Estágio", do sítio do MEC versa sobre o oferecimento de estágios no exterior. 0 Parecer CNE/CES no $416^{22}$, emitido em $8 / 11 / 2012$, pode ser debatido levando-se em conta dois fatores: por um lado, a lei do estágio configura instrumento legal do governo brasileiro para regulamentar a formação profissional a partir de sua soberania; e por outro, a formação em ambiente profissional não regulamentado pelas leis nacionais (securitárias, trabalhistas, previdenciárias, e outras) pode não representar a mesma contribuição formativa que a atividade realizada em território nacional. Justamente por isso encontramos a orientação:

Uma vez preservado o caráter nacional de uma entidade que pretenda atuar como parte concedente, ainda que a sua localização física se dê fora dos limites territoriais do Brasil seria possível pensar, em tese, na possibilidade da realização do estágio curricular no exterior $^{22: 1 .}$. 


\section{CONCLUSÃo}

Cumprindo os objetivos de esclarecer o debate sobre políticas institucionais de estágio na UFTM e apresentar os fundamentos legais às CIEs e ao COENS, o levantamento logrou êxito em apresentar alguns diagnósticos incontornáveis:

- quando se trata da organização dos estágios, a legislação atual atribui autoridade maior às instituições de ensino do que permite ao MEC, ao Ministério do Trabalho, aos conselhos profissionais e até às instituições concedentes;

- quando se trata de universidades, a expressão "responsabilidade da instituição de ensino" frequentemente registrada no marco legal significa, na experiência didática cotidiana, autoridade quase plena dos colegiados de cursos;

- pelas decisões do CNE (na Câmara de Educação Básica, de Educação Superior ou no Conselho Pleno), o NuEG não parece isolado quando reivindica debate mais intenso sobre as políticas institucionais de estágio em instituições complexas como as universidades.

Ao se procurar na legislação oficial determinações que facilitem ver o que é permitido ou não nas situações de estágio, invariavelmente se encontra o conceito de "projeto pedagógico" envolvido. Ajustes e alterações nos regulamentos e normas das universidades para atenderem demandas específicas de cursos podem ser efetivados a qualquer momento, desde que existam: a) conhecimento e competência para realizar os esclarecimentos necessários à comunidade; b) sólido compromisso político com os princípios e o estatuto da universidade.

Como visto, não é simples a tarefa de pensar política acadêmica a partir da forma como a autonomia é exercida pelos colegiados atualmente, porém é a única alternativa para não transformar a identidade de uma IES em peça de ornamentação. Parece que na prática a teoria tem sido bem outra.

\section{REFERÊNCIAS}

1. Brasil. Lei no 11788 de 25 de setembro de 2008. Dispõe sobre o estágio de estudantes [Internet]. Brasília, DF; 2008. [acesso em 2014 abr. 29]. Disponível em: http://www.planalto.gov.br/ccivil_03/_ato2007-

2010/2008/lei/l11788.htm

2. Brasil. Lei no 9394 de 20 de dezembro de 1996. Estabelece as diretrizes e bases da educação nacional [Internet]. Brasília, DF; 1996. [acesso em 2014 abr. 29]. Disponível http://portal.mec.gov.br/arquivos/pdf/ldb.pdf

3. Pimenta SG, Lima MSL. Estágio e docência: diferentes concepções. Rev. Poíesis. 2005/2006; 3(3/4):5-24. [acesso em 2014 abr. 29]. Disponível em: http://www.cead.ufla.br/sisgap/cadSelecao/editais/out ros/Estagio\%20e\%20docencia:\%20diferentes\%20conce pcoesEdital062013_2.pdf

4. Mazzotti T, Oliveira RJ. Ciência(s) da educação. Coleção Retórica e Argumentação na Pedagogia. Vol. 5. 2a ed. Marília-SP: Poiesis, 2013. 135p.

5. Brasil. Conselho Nacional de Educação. Parecer CNE/CEB no 35 de 05 de novembro de 2003. Normas para a organização e realização de estágio de alunos do Ensino Médio e da Educação Profissional [Internet]. Diário Oficial [da] República Federativa do Brasil. 2004 jan. 20 [acesso em 2014 abr 29]. Disponível em: http://portal.mec.gov.br/cne/arquivos/pdf/pceb35_03. pdf

6. Brasil. Constituição de 1988. Constituição da República Federativa do Brasil. Brasília: Senado Federal; 1988.

7. Brasil. Conselho Nacional de Educação. Parecer CNE/CES no 228 de 04 de agosto de 2004. Consulta sobre reformulação curricular dos Cursos de Graduação [Internet]. Diário Oficial [da] República Federativa do Brasil. 2004 set. 24 [acesso em 2014 abr 29]. Disponível em:http://portal.mec.gov.br/cne/arquivos/pdf/pceb35_ 03.pdf

8. Brasil. Conselho Nacional de Educação. Parecer CNE/CES no 744 de 03 de dezembro de 1997. Orientações para cumprimento do artigo 65 da Lei 9.394/96 - Prática de Ensino [Internet]. [Acesso em 2014 abr 29]. Disponível em: http://portal.mec.gov.br/cne/arquivos/pdf/1997/pces7 44_97.pdf

9. Brasil. Conselho Nacional de Educação. Parecer CNE/CES no 503 de 03 de agosto de 1998. Solicita esclarecimentos da Lei 9.394/96 no que se refere às normas para realização dos estágios supervisionados dos alunos regularmente matriculados no ensino médio ou superior. [Internet]. Diário Oficial [da] República Federativa do Brasil. 1998 ago. 24 [acesso em 2014 abr 29]. Disponível em: http://portal.mec.gov.br/cne/arquivos/pdf/1998/pces5 03_98.pdf

10. Brasil. Conselho Nacional de Educação. Resolução CNE/CP $\mathrm{n}^{\mathrm{o}} 1$ de 18 de fevereiro de 2002. Institui Diretrizes Curriculares Nacionais para a Formação de Professores da Educação Básica, em nível superior, curso de licenciatura, de graduação plena [Internet]. [Acesso em 2014 abr 29]. Disponível em: http://portal.mec.gov.br/seesp/arquivos/pdf/res1_2.pd f. 
11. Brasil. Conselho Nacional de Educação. Parecer CNE/CES no 33 de 01 de fevereiro de 2007. Consulta sobre a carga horária do curso de graduação em Enfermagem e sobre a inclusão do percentual destinado ao Estágio Supervisionado na mesma carga horária. [Internet]. Diário Oficial [da] República Federativa do Brasil. 2007 ago. 27 [Acesso em 2014 abr 29]. Disponível em:http://portal.mec.gov.br/cne/arquivos/pdf/2007/p ces033_07.pdf

12. Brasil. Conselho Nacional de Educação. Parecer CNE/CES no 362 de 01 de setembro de 2011. Solicitação para que seja verificada a possibilidade de se aperfeiçoar a redação do art. 7ํ, § 1ํㅡㄹ da Resolução CNE/CES no 9/2004, que trata dos núcleos de prática jurídica. [Internet]. Diário Oficial [da] República Federativa do Brasil. 2012 mai. 30 [Acesso em 2014 abr 29]. Disponível em:http://portal.mec.gov.br/index.php?option=com_doc man\&task=doc_download\&gid=9409\&Itemid=

13. Brasil. Conselho Nacional de Educação. Parecer CNE/CES no 15 de 02 de fevereiro de 2005. Solicitação de esclarecimento sobre as Resoluções CNE/CP nºs $1 / 2002$, que institui Diretrizes Curriculares Nacionais para a Formação de Professores da Educação Básica, em nível superior, curso de licenciatura, de graduação plena, e 2/2002, que institui a duração e a carga horária dos cursos de licenciatura, de graduação plena, de Formação de Professores da Educação Básica, em nível superior. [Internet]. Diário Oficial [da] República Federativa do Brasil. 2005 mai. 13 [Acesso em 2014 abr 29]. Disponível em:http://portal.mec.gov.br/cne/arquivos/pdf/pces001 5_05.pdf

14. Brasil. Conselho Nacional de Educação. Parecer CNE/CES no 23 de 02 de fevereiro de 2006. Aprecia a Indicação CNE/CES no 8/2005, que propõe a revisão da Resolução CNE/CES $n^{\circ} 1 / 2005$, na qual são estabelecidas normas para o apostilamento, em diplomas de cursos de graduação em Pedagogia, do direito ao exercício do magistério nos anos iniciais do Ensino Fundamental. [Internet]. Diário Oficial [da] República Federativa do Brasil. 2006 mar. 16 [Acesso em 2014 abr 29]. Disponível em: http://portal.mec.gov.br/cne/arquivos/pdf/pces023_06 .pdf

15. Brasil. Conselho Nacional de Educação. Resolução CNE/CP $\mathrm{n}^{\circ} 2$ de 19 de fevereiro de 2002. Institui a duração e a carga horária dos cursos de licenciatura, de graduação plena, de formação de professores da Educação Básica em nível superior. [Internet]. [Acesso em 2014 abr 29]. Disponível em: http://portal.mec.gov.br/seesp/arquivos/pdf/res1_2.pd $\mathrm{f}$

16. Brasil. Conselho Nacional de Educação. Parecer CNE/CES no 232 de 06 de agosto de 2002. Consulta sobre o art. 65 da LDB 9.394/96 e Parecer CES/CNE 744/97, que tratam da prática de ensino nos cursos de licenciatura. [Internet]. Diário Oficial [da] República Federativa do Brasil. 2002 set. 2 [Acesso em 2014 abr 29]. Disponível em: http://portal.mec.gov.br/cne/arquivos/pdf/2002/pces2 32_02.pdf
17. Brasil. Conselho Nacional de Educação. Parecer CNE/CES n 0197 de 07 de julho de 2004. Consulta, tendo em vista o art. 11 da Resolução CNE/CP 1/2002, referente às Diretrizes Curriculares Nacionais para a Formação de Professores da Educação Básica em nível superior, curso de licenciatura, de graduação plena. [Internet]. Diário Oficial [da] República Federativa do Brasil. 2005 abr. 5 [Acesso em 2014 abr 29]. Disponível em:http://portal.mec.gov.br/cne/arquivos/pdf/pces197 -04.pdf

18. Brasil. Conselho Nacional de Educação. Parecer CNE/CEB no 34 de 10 de novembro de 2004. Consultas sobre estágio supervisionado de alunos da Educação Profissional, do Ensino Médio, inclusive na modalidade de Educação Especial, e de Educação de Jovens e Adultos. [Internet]. Diário Oficial [da] República Federativa do Brasil. 2005 mar. 10 [Acesso em 2014 abr 29]. Disponível em: http://portal.mec.gov.br/cne/arquivos/pdf/pceb034_04 .pdf

19. Brasil. Conselho Nacional de Educação. Resolução CNE/CEB no 1 de 21 de janeiro de 2004. Estabelece Diretrizes Nacionais para a organização e a realização de Estágio de alunos da Educação Profissional e do Ensino Médio, inclusive nas modalidades de Educação Especial e de Educação de Jovens e Adultos. [Internet]. [Acesso em 2014 abr 29]. Disponível em: http://portal.mec.gov.br/seesp/arquivos/pdf/res1.pdf 20. Brasil. Conselho Nacional de Educação. Resolução CNE/CEB no 2 de 04 de abril de 2005. Modifica a redação do $§ 3^{\circ}$ do artigo 5o da Resolução CNE/CEB no 1/2004, até nova manifestação sobre estágio supervisionado pelo Conselho Nacional de Educação. [Internet]. [Acesso em 2014 abr 29]. Disponível em: http://portal.mec.gov.br/cne/arquivos/doc/rceb02_05. doc

21. Brasil. Conselho Nacional de Educação. Parecer CNE/CEB no 20 de 08 de novembro de 2012. Consulta sobre a legitimidade da realização das atividades de vivência e prática profissional em ambientes de empresas de setor produtivo [Internet]. Diário Oficial [da] República Federativa do Brasil. 2013 fev. 04 [Acesso em 2014 abr 29]. Disponível em: http://portal.mec.gov.br/index.php?option=com_docma n\&task=doc_download\&gid=11940\&Itemid=

22. Brasil. Conselho Nacional de Educação. Parecer CNE/CES no 416 de 08 de novembro de 2012. Consulta sobre estágio no exterior. [Internet]. Acesso em $2014 \mathrm{abr}$ $29 . \quad$ Disponível em: http://portal.mec.gov.br/index.php?option=com_docma n\&task=doc_download\&gid=12284\&Itemid=.

CONTRIBUIÇÕES
Érico Lopes Pinheiro de Paula foi
responsável pelo levantamento documental
e construção do artigo.

